\title{
Longitudinal Data on Growth and Final Height in Diabetic Children
}

\author{
MARC V. L. DU CAJU, RAOUL P. ROOMAN, AND LIEVE OP DE BEECK
}

Department of Pediatrics, University Hospital Antwerp, Antwerp, Belgium \begin{abstract}
The available data on growth in children with insulin-
Tependent diabetes mellitus are conflicting and are mainly derived from cross-sectional studies. In this longitudinal study, height, weight, skeletal age, and pubertal development were recorded until final height was attained in 46 children (22 girls and 24 boys) with onset of diabetes before the age of $10 \mathrm{y}$. At the onset of diabetes, height SD score (SDS) averaged 0.41 in girls and 0.56 in boys, which was normal when corrected for the secular trend. Prepubertal growth was unaffected in both sexes. Diabetic boys had a marked delay in onset of puberty (mean age at genitalia stage 2: $13.7 \mathrm{y}$ ) but attained a normal final height (final height SDS: $0.48 \pm 0.89$ ). In girls final height was slightly reduced (height SDS $0.27 \pm 0.97$ ) due to a suboptimal pubertal growth spurt. Mean pubertal height gain in girls was $16.6 \mathrm{~cm}$ and
\end{abstract}

mean age at breast stage 2 was 11.6 y. Diabetic girls also tended to become obese during puberty. Skeletal maturation was normal at all ages. These data suggest that conventional therapy does not guarantee optimal growth, especially in girls. (Pediatr Res 38: 607-611, 1995)

SDS, SD score

Abbreviations

BMI, body mass index

TPHG, total pubertal height gain

$\mathbf{H b A}_{1 \mathrm{c}}$, hemoglobin $\mathrm{A}_{1 c}$

$\mathbf{B}_{2}$, breast stage 2

$\mathbf{G}_{2}$, genitalia stage 2
Impaired growth, obesity, and delayed puberty have been described in children with very poorly controlled diabetes such as the Mauriac syndrome. The introduction of improved insulin preparations and home blood glucose monitoring has resulted in a much better metabolic control. The question whether diabetes, well treated with conventional means, still compromises the growth of diabetic children, remains controversial. Many studies claim that longitudinal growth is impaired in diabetic children (1-7). Some investigators have observed catch-up growth in poorly controlled diabetic children after a better degree of control had been achieved (8-10). Other authors claim that growth remains impaired, irrespective of the degree of metabolic control $(1,2,11)$. Their pessimistic view is supported by data from identical twins in whom one twin developed diabetes before puberty. Compared with the normal twin, growth impairment persisted even with adequate therapy (3). In contrast, several other studies have shown that children in good metabolic control have a growth pattern which is identical to that in control children $(8,9,12,13)$.

There also remains controversy about which growth phase is impaired in diabetic children. In some children with early onset of diabetes prepubertal growth was claimed to be blunted (11,

Received December 12, 1994; accepted March 16, 1995.

Manuscript dedicated to Professor H.K.A. Visser in honor of his retirement.

Correspondence: Marc V. L. Du Caju, Department of Pediatrics, University Hospital Antwerp, Wilrijkstraat, 10, B-2650 Antwerp, Belgium.
14). In other studies, the reduction in height has largely been attributed to a delayed and/or blunted pubertal growth spurt (2, $3,7,11)$.

We therefore analyzed in a longitudinal study growth and pubertal development in a group of 46 diabetic children who were followed up until final height was attained. Childhood growth was evaluated in an additional cohort of 27 diabetic children followed longitudinally until the age of $10 \mathrm{y}$.

\section{METHODS}

Growth and development were analyzed longitudinally in two cohorts of patients with insulin-dependent diabetes mellitus. The first cohort consisted of 46 children ( 22 girls and 24 boys) who were followed from an age below $10 \mathrm{y}$ until final height. Early prepubertal growth was recorded for at least 3 y in a second cohort of 27 children (11 girls, 16 boys) in whom diabetes started before the age of 7 . Exclusion criteria were non-Caucasian origin, other endocrine disorders, chromosomal aberrations, and enteropathies. Standard guidelines for treatment were provided to all patients. All children were treated with conventional insulin therapy consisting of two daily injections of a combination of long-acting and short-acting insulin. The insulin dosage was adjusted to prevent glucosuria and hyperglycemia. Metabolic control of diabetes was assessed by the level of $\mathrm{HbA}_{1 c}$, which was determined by ion-exchange 
column chromatography with reference range of $4.2-5.7 \%$ in nondiabetic children.

Standing height was measured at least every 6 mo by the same investigator using a fixed Harpenden stadiometer. Growth data were analyzed after transformation into SDS according to Tanner et al. (15). Target height was calculated using the equation devised by Tanner and corrected for the secular trend: for boys: (father's height + mother's height + $13 \mathrm{~cm}) / 2+2.5 \mathrm{~cm}$; for girls: (father's height + mother's height $-13 \mathrm{~cm}) / 2+2,5 \mathrm{~cm}$. Pubertal development was rated according to Marshall and Tanner $(16,17)$. The onset of puberty was defined as the appearance of a testicular volume of $4 \mathrm{~mL}$ or more $\left(\mathrm{G}_{2}\right)$ in boys and budding stage $\left(\mathrm{B}_{2}\right)$ in girls. TPHG was calculated by substracting the height at onset of puberty from the final height. Final height was defined as a height increment of less than $1 \mathrm{~cm}$ over the last year. BMI was calculated by dividing weight in kilograms by the square of the height in meters. BMI-SDS was calculated using the reference values published by Rolland-Cachera et al. (18). Skeletal age was assessed by the method of Greulich and Pyle (19) and predicted adult height was estimated by the method of Bayley and Pinneau (see Ref. 19).

Statistical analysis was performed using the Wilcoxon matched pairs signed rank test. Differences were determined by two-tailed tests and were considered to be significant at the $p$ $<0.05$ level. The results were expressed as mean $\pm \mathrm{SD}$.

\section{RESULTS}

Table 1 summarizes the auxologic data from cohort 1 . Mean height SDS at the onset of diabetes was $0.41 \pm 0.99$ in girls and $0.56 \pm 0.68$ in boys. Mean final height SDS was lower than the height SDS at onset $(0.27 \pm 0.97$ in girls and $0.48 \pm$ 0.89 in boys). Comparison of the height SDS at onset with the height SDS at final height for each individual did not show a significant difference ( $p=0.33$ for girls; $p=0.36$ for boys). Final height was significantly lower than the target height in girls $(163.7 \pm 5.9 \mathrm{~cm}$ and $167.1 \pm 5.0 \mathrm{~cm}$, respectively; $p<$ $0.05)$. In contrast, the boys attained a final height comparable to their target height $(177.1 \pm 6.1 \mathrm{~cm}$ and $178.1 \pm 6.0 \mathrm{~cm}$, respectively). The individual differences between final height SDS and height SDS at diagnosis were not correlated with the duration of diabetes.

Prepubertal growth until the age of $10 \mathrm{y}$ was little affected, because the height SDS at $10 \mathrm{y}$ was not different from the height SDS at onset. This finding was corroborated by the analysis of the growth parameters in a separate cohort (cohort

Table 1. Growth data in children with diabetes (mean $\pm S D$ )

\begin{tabular}{lcc}
\hline & Girls $(n=22)$ & Boys $(n=24)$ \\
\hline Age at onset diabetes, y & $7.5 \pm 2.6$ & $7.4 \pm 3.0$ \\
Age at onset puberty, y & $11.6 \pm 1.0$ & $13.7 \pm 1.1$ \\
Age at menarche, $y$ & $13.6 \pm 1.0$ & \\
Height SDS at onset diabetes & $0.41 \pm 0.99$ & $0.56 \pm 0.68$ \\
Height SDS at the age of $10 \mathrm{y}$ & $0.38 \pm 1.05$ & $0.42 \pm 0.73$ \\
Height SDS at onset puberty & $0.15 \pm 1.25$ & $-0.17 \pm 1.13$ \\
Height SDS at final height & $0.27 \pm 0.97$ & $0.48 \pm 0.89$ \\
TPHG, cm & $16.5 \pm 3.6$ & $19.9 \pm 4.2$ \\
\hline
\end{tabular}

2) of young children in whom height SDS at the age of $7 \mathrm{y}$ was not significantly different from the height SDS at the age of 10 y (data not shown).

The evolution of height SDS from the age of 10 onward was different in boys compared with girls (Fig. 1). During the last $2 \mathrm{y}$ of prepubertal growth, height SDS decreased significantly in boys. Mean height SDS in boys at $\mathrm{G}_{2}$ was $-0.17 \pm 1.13(p$ $<0.001$ when compared with height SDS at onset and height SDS at final height) and in girls at $\mathrm{B}_{2} 0.15 \pm 1.25$ (NS when compared with height SDS at onset or final height). Once puberty had started, height SDS returned to values attained at final height within $2 \mathrm{y}$.

The decline in height SDS is explained by the delay in onset of puberty which is more pronounced in boys than in girls. Figure 2 compares the cumulative distribution curve for the age of attaining $B_{2} / G_{2}$ in our patients with the reference data collected by Largo and Prader $(20,21)$. In diabetic boys, the mean age for attaining $G_{2}$ was $13.7 \pm 1.1 \mathrm{y}$ as opposed to 11.2 $\pm 1.5 \mathrm{y}$ in control boys. This finding was not explainable by a constitutional delay in puberty. In only 4 out of the 24 boys, one of the parents had a history of delayed puberty. After exclusion of these 4 boys, the mean age for attaining $G_{2}$ was still $13.5 \pm 1.1 \mathrm{y}$. On the other hand, the mean age for attaining $\mathrm{B}_{2}$ was $11.6 \pm 1.0 \mathrm{y}$ in this study compared with $10.9 \mathrm{y}$ in the

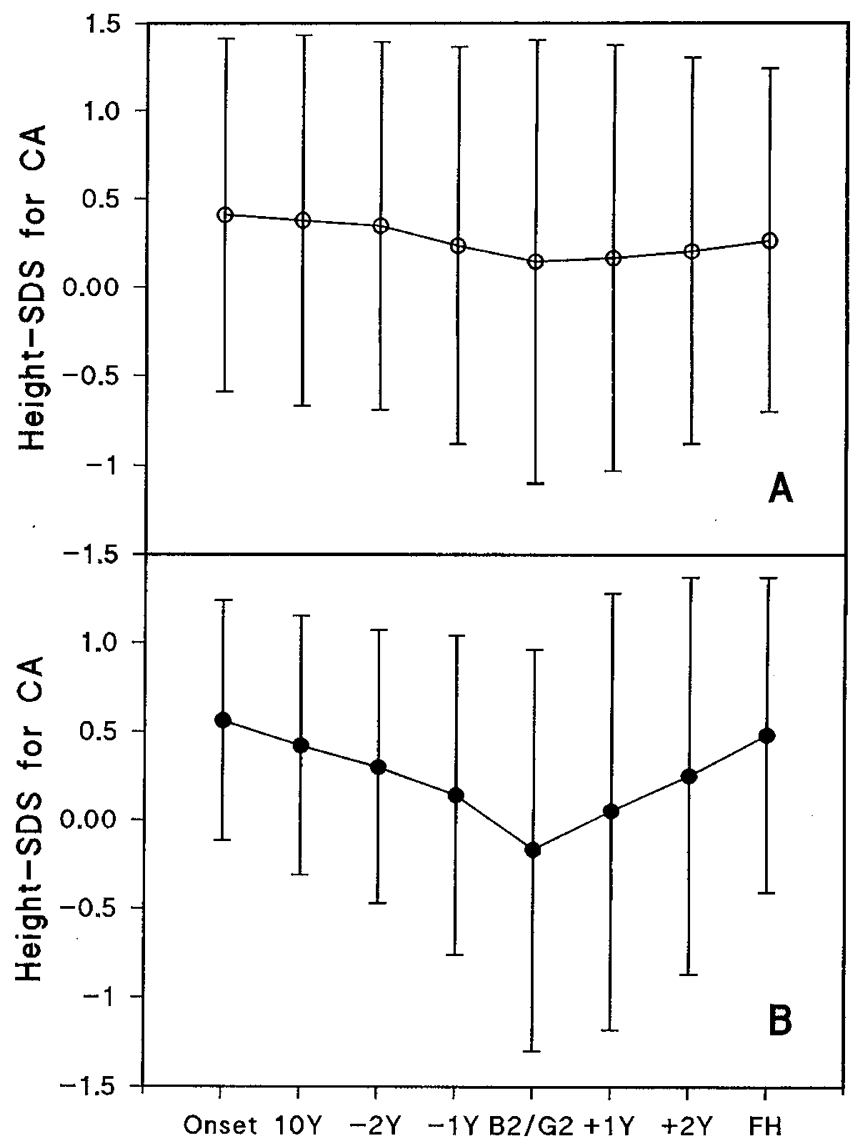

Figure 1. Evolution of the height SDS for chronologic age (mean \pm SD) in 22 girls $(A)$ and 24 boys $(B)$ followed longitudinally from onset of diabetes to final height. Height SDS was calculated at onset of diabetes, at the age of 10 $y$, at the age of onset of puberty $\left(B_{2} / G_{2}\right), 1$ and $2 y$ before and after $B_{2} / G_{2}$ and at final height 


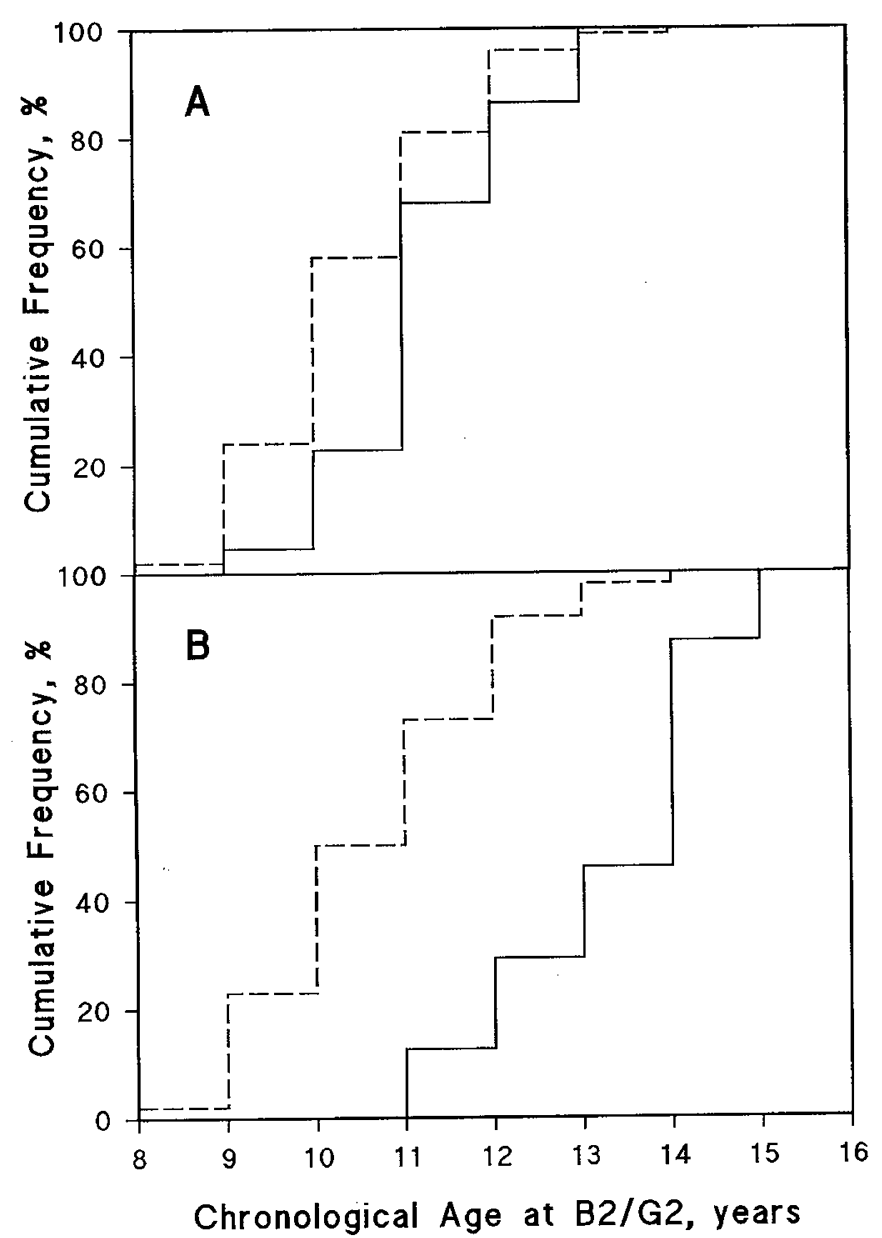

Figure 2. Cumulative frequency data of chronologic age the onset of puberty $\left(\mathrm{B}_{2} / \mathrm{G}_{2}\right)$ in girls $(A)$ and boys $(B)$. The solid lines represent the data in diabetic children, the broken lines represent the data in normal children published by Largo and Prader $(20,21)$.

controls. Only 2 girls had a family history of pubertal delay. The mean age at menarche $(13.6 \pm 1.0 \mathrm{y})$ was comparable with the reference data.

No relation was found between the age at onset of diabetes and the chronologic or skeletal age at $\mathrm{G}_{2} / \mathrm{B}_{2}$ in both sexes. In boys, a positive correlation between the age at onset of puberty and the mean insulin dosage during the preceding $2 \mathrm{y}$ was observed $(r=0.56 ; p<0.005)$.

The metabolic control of diabetes assessed by $\mathrm{HbA}_{1 \mathrm{c}}$ levels and the daily insulin dosage before and after the onset of puberty are shown in Table $2 . \mathrm{HbA}_{1 \mathrm{c}}$ levels were usually higher in boys than in girls but did not vary widely during puberty. The dosage of insulin/kg body weight increased with the onset of puberty in both sexes.

TPHG averaged $16.5 \pm 3.6 \mathrm{~cm}$ in girls and $19.9 \pm 4.2 \mathrm{~cm}$ in boys and was negatively correlated with the chronologic age at the onset of puberty (Fig. 3). Multiple regression analysis indicated that TPHG in girls was mainly dependent on the age at onset of puberty, which accounted for $22 \%$ of the variability $(p<0.05)$. TPHG was not influenced by the mean $\mathrm{HbA}_{1 \mathrm{c}}$ value, the mean insulin dosage, and the increment in BMI during puberty, nor by duration of diabetes before the onset of puberty. In boys, TPHG was dependent on the age at onset of puberty and to a lesser extent on the insulin dosage. Together they accounted for $43 \%$ of the variability $(p<0.005)$. The other factors did not influence TPHG.

Girls tended to gain excessively in weight during their pubertal height spurt. Their BMI-SDS increased from an average of $0.26 \pm 0.98$ at $\mathrm{B}_{2}$ to $0.69 \pm 0.97$ at attaining final height. Finally, skeletal age was comparable to chronologic age at $10 \mathrm{y}$ and at $\mathrm{B}_{2} / \mathrm{G}_{2}$ (Table 3). The mean difference between final height and predicted adult height at the age of $10 \mathrm{y}$ was $1.2 \pm 3.4 \mathrm{~cm}$ in girls and $-0.3 \pm 4.4 \mathrm{~cm}$ in boys. At the time of onset of puberty, the difference averaged $0.9 \pm 2.7 \mathrm{~cm}$ in girls and $-1.2 \pm 5.0 \mathrm{~cm}$ in boys. At the age of menarche, final height minus predicted adult height had a mean of $-1.7 \pm 1.8$ $\mathrm{cm}$.

\section{DISCUSSION}

Because of the lack of appropriate longitudinal growth charts in Belgium we used the reference data for height published by Tanner et al. (15) in 1966. Since the publication of this report, a significant secular trend in height has been observed. In the Dutch surveys of 1965 and 1990, the height of children younger than $10 \mathrm{y}$ differed by an average of $1.4 \mathrm{~cm}$ (22). Within our own population the mean height for normal 18 -y-old boys in 1990 was $177.5 \mathrm{~cm}$, which was $2.8 \mathrm{~cm}$ higher than the average of the Tanner growth standards. Consequently, the apparent increased stature at the onset of diabetes and at adult age can be attributed to the secular trend. Our data therefore do not support the notion from the literature that diabetic children are taller $(5,7,14,23-25)$ or smaller $(26,27)$ than average at the onset of their disease, but corroborate earlier reports (2-4) of normal height in newly diagnosed diabetic children.

In both female and male subjects, final height SDS was slightly reduced but not statistically different from the height SDS at onset of diabetes. However, large differences ranging from +2.4 to -2.0 SDS were observed among patients. This

Table 2. $H b A_{1 c}$ levels and daily insulin dosage during the prepubertal and pubertal period (mean $\left.\pm S D\right)$

\begin{tabular}{|c|c|c|c|c|c|c|}
\hline $\begin{array}{l}\text { Interval with } \\
\text { stage } B_{2} / G_{2}\end{array}$ & $-2 y$ & $-1 \mathrm{y}$ & $0 \mathrm{y}$ & $+1 \mathrm{y}$ & $+2 y$ & Final height \\
\hline \multicolumn{7}{|l|}{$\mathrm{HbA}_{\mathrm{lc}}(\%)$} \\
\hline Girls & $9.1 \pm 2.4$ & $8.9 \pm 1.9$ & $8.8 \pm 2.6$ & $8.6 \pm 1.6$ & $8.9 \pm 1.4$ & $9.1 \pm 1.8$ \\
\hline Boys & $9.0 \pm 1.6$ & $9.7 \pm 1.2$ & $10.1 \pm 2.1$ & $9.8 \pm 1.8$ & $10.1 \pm 1.8$ & $9.8 \pm 1.9$ \\
\hline \multicolumn{7}{|l|}{ Insulin $\mathrm{U} / \mathrm{kg} / \mathrm{d}$} \\
\hline Girls & $0.85 \pm 0.24$ & $0.79 \pm 0.27$ & $0.90 \pm 0.22$ & $1.03 \pm 0.29$ & $1.07 \pm 0.23$ & $0.99 \pm 0.31$ \\
\hline Boys & $0.76 \pm 0.21$ & $0.81 \pm 0.19$ & $0.94 \pm 0.23$ & $0.95 \pm 0.18$ & $0.99 \pm 0.18$ & $0.98 \pm 0.19$ \\
\hline
\end{tabular}




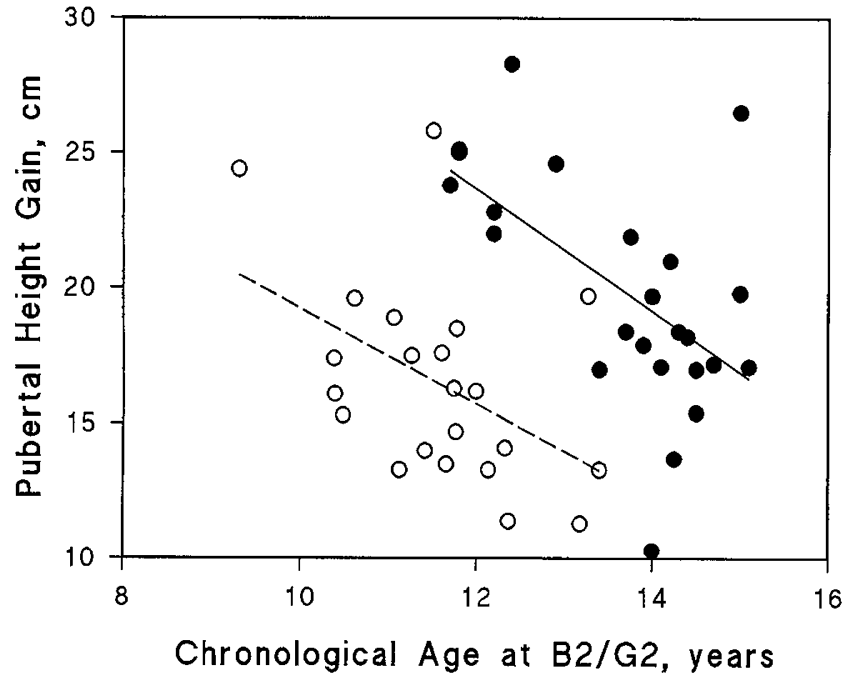

Figure 3. Relationship between TPHG and chronologic age at onset of puberty $\left(\mathrm{B}_{2} / \mathrm{G}_{2}\right)$ in diabetic girls (open circles; $r=-0.47 ; p<0.05$ ) and boys (closed circles; $r=-0.57 ; p<0.05$ )

Table 3. Skeletal age and height prediction at different ages in children with diabetes (mean $\pm S D$ )

\begin{tabular}{lcc}
\hline & Girls $(n=22)$ & Boys $(n=24)$ \\
\hline Skeletal age at age 10, y & $10.0 \pm 0.8$ & $10.1 \pm 0.9$ \\
Skeletal age at onset puberty, y & $11.2 \pm 0.7$ & $13.2 \pm 0.7$ \\
Skeletal age at menarche, y & $13.3 \pm 0.5$ & \\
FH minus PAH at age 10 y, cm & $1.2 \pm 3.4$ & $-0.3 \pm 4.4$ \\
FH minus PAH at onset puberty, cm & $0.9 \pm 2.6$ & $-1.2 \pm 5.0^{*}$ \\
FH minus PAH at menarche, cm & $-1.7 \pm 1.8$ & \\
\hline
\end{tabular}

$\mathrm{FH}=$ final height; $\mathrm{PAH}$ : predicted adult height; ${ }^{*} n=19$.

variability was not related to the duration of the disease. Only a few data on final height in diabetic patients were published in the literature. Tattersall and Pyke (3) showed that final height in patients with diabetes diagnosed before puberty, was $5 \mathrm{~cm}$ smaller than the height of their unaffected twin. In longitudinal studies Salardi et al. (7) and Dunger and Brown (11) reported a small significant reduction in final height in children with early onset diabetes. In contrast, Jackson (8) found a normal adult height in patients with metabolically well controlled diabetes. Some authors have suggested that this height loss occurs in the prepubertal growth phase $(3,11,14)$. In our patients there was no loss of growth before the age of $10 \mathrm{y}$ in both cohorts. Height SDS was markedly reduced at the onset of puberty, especially in boys. In girls stage $\mathbf{B}_{2}$ was attained on average $1 \mathrm{y}$ later than in the control group reported by Largo and Prader $(20,21)$. Boys had a delayed onset of puberty reaching stage $G_{2}$ almost 3 y later than controls. This marked delay caused a steep decline in height SDS during the last prepubertal years and may explain the prepubertal height loss reported in previous studies. Delayed puberty in boys was also reported by Jivani and Rayner (2). In contrast, Salardi et al. (7) found a mean age at stage $\mathrm{G}_{2}$ of $11.3 \mathrm{y}$ and Clarson et al. (13) reported a mean age of $11.9 \mathrm{y}$. The mean age at stage $\mathrm{B}_{2}$ of $11.6 \mathrm{y}$ in our study was consistent with the data reported by Clarson et al. (13). The mean age at menarche $(13.7 \mathrm{y})$ was intermediate between the values reported by Clarson and those reported by Kjaer et al. (28).
Growth during puberty was calculated as TPHG as recommended by Bourguignon (29). TPHG averaged $16.5 \mathrm{~cm}$ in diabetic girls and $19.9 \mathrm{~cm}$ in diabetic boys and progressively decreased with the age at onset of puberty. There are, however, no reference data for TPHG as a function of chronologic age at onset of puberty. Tanner et al. (15) calculated an average TPHG of $25 \mathrm{~cm}$ in girls and $28 \mathrm{~cm}$ in boys. Based on these data we assume that TPHG in diabetic girls was clearly insufficient. In boys, TPHG had to be corrected for their pubertal delay. If we extrapolated the regression line between TPHG and age at onset of puberty (Fig. 3) to the age of $11.2 \mathrm{y}$ (which is the mean age at onset of puberty in normal subjects) TPHG practically equaled the normal range. In both diabetic girls and boys, no relationship was observed between TPHG and their relatively, impaired metabolic control. These results are in agreement with the findings of Salardi et al. (7) who reported a mean TPHG of $14.9 \mathrm{~cm}$ in diabetic girls and a mean of $28.7 \mathrm{~cm}$ in boys in the presence of a wide range of $\mathrm{HbA}_{1 \mathrm{c}}$ levels. A blunted pubertal growth spurt in girls was also reported by Vanelli et al. (30). The reduction in TPHG in girls probably explains why the diabetic girls in our study did not reach their target height.

The factor which influenced TPHG, as demonstrated by multiple regression analysis, was the age at onset of puberty in both sexes. In boys the insulin dosage was the second influencing factor.

Most girls gained more weight than height during puberty. Even when corrected for the normal increase in BMI during puberty, most of our diabetic girls displayed a tendency toward obesity. This association of overweight and height reduction was also described by other investigators $(4,6)$. Our data on skeletal maturation confirm previous reports that demonstrated a normal skeletal age for age in diabetic children $(4,7,12)$.

In conclusion, the results of this longitudinal analysis showed that linear growth in diabetic girls was slightly reduced due to a blunted pubertal growth spurt. Diabetic girls also had a tendency to become obese during puberty. Boys with diabetes had a marked delay in the onset of puberty but attained a normal final height. Our data on metabolic control did not demonstrate any correlation with TPHG. However, the range of $\mathrm{HbA}_{1 \mathrm{c}}$ levels within this population might be too narrow to definitively exclude the possibility that a better metabolic control obtained by intensive insulin therapy can improve final height.

\section{REFERENCES}

1. Herber SM, Dunsmore IR 1988 Does control affect growth in diabetes mellitus? Acta Paediatr Scand 77:303-305

2. Jivani SKM, Rayner PHW 1973 Does control influence the growth of diabetic children? Arch Dis Child 48:109-115

3. Tattersall RB, Pyke DA 1973 Growth in diabetic children. Studies in identical twins. Lancet 2:1105-1109

4. Thon A, Heinze E, Feilen K-D, Holl RW, Schmidt H, Koletzko S, Wendel U, Nothjunge J 1992 Development of height and weight in children with diabetes mellitus: report on two prospective multicentre studies, one cross-sectional, one longitudinal. Eur J Pediatr 151:258-262

5. Edelsten AD, Hughes IA, Oakes S, Gordon IRS, Savage DCL 1981 Height and skeletal maturity in children with newly-diagnosed juvenile-onset diabetes. Arch Dis Child 56:40-44

6. Evans N, Robinson VP, Lister J 1972 Growth and bone age of juvenile diabetics. Arch Dis Child 47:589-593

7. Salardi S, Tonioli S, Tassoni P, Tellarini M, Mazzanti L, Cacciari E 1987 Arch Dis Child 62:57-62 
8. Jackson RL 1984 Growth and maturation of children with insulin-dependent diabetes mellitus. Pediatr Clin North Am 31:545-567

9. Petersen HD, Korsgaard B, Deckert T, Nielsen E 1978 Growth, body weight and insulin requirement in diabetic children. Acta Paediatr Scand 67:453-457

10. Rudolf MCJ, Sherwin RS, Markowitz R, Bates SE, Genel M, Hochstadt J, Tamborlane WV 1982 Effect of intensive insulin treatment on linear growth in the young diabetic patient. J Pediatr 101:333-339

11. Dunger DB, Brown M 1990 Diabetes and growth in puberty. Growth Matters 5:10-14

12. Birkbeck JA 1972 Growth in juvenile diabetes mellitus. Diabetologia 8:221-224

13. Clarson C, Daneman D, Ehrlich RM 1985 The relationship of metabolic control to growth and pubertal development in children with insulin-dependent diabetes. Diabetes Res 2:237-241

14. Wise JE, Kolb EL, Sauder SE 1992 Effect of glycemic control on growth velocity in children with IDDM. Diabetes Care 15:826-830

15. Tanner JM, Whitehouse RH, Takaishi M 1966 Standards from birth to maturity for height, weight, velocity, and weight velocity: British Children, 1965, Part I. Arch Dis Child 41:454-471

16. Marshall WA, Tanner JM 1969 Variations in pattern of pubertal changes in girls. Arch Dis Child 44:291-303

17. Marshall WA, Tanner JM 1970 Variations in the pattern of pubertal changes in boys. Arch Dis Child 45:13-23

18. Rolland-Cachera M-F, Sempé $M$, Guilloud-Bataille $M$, Patois E, PéquignotGuggenbuhl F, Fautrad V 1982 Adiposity indices in children. Am J Clin Nutr 36:178-184

19. Greulich WN, Pyle S 1983 Radiographic Atlas of Skeletal Development of the Hand and Wrist, 2nd Ed. Stanford University Press, Stanford, CA
20. Largo RH, Prader A 1983 Pubertal development in Swiss girls. Helv Paediatr Acta 38:229-243

21. Largo RH, Prader A 1983 Pubertal development in Swiss boys. Helv Paediatr Acta 38:211-228

22. Roede MJ 1985 Growth diagrams 1980. Tijdschr Soc Gezondheidszorg Suppl 63:10-34

23. Drayer NM 1974 Height of diabetic children at onset of symptoms. Arch Dis Child 49:616-620

24. Songer TJ, Laporte RE, Tajima N, Orchard TJ, Rabin BS, Eberhardt MS, Dorman JS, Cruickshanks KJ, Cavender DE, Becker DJ, Drash AL 1986 Height at diagnosis of insulin dependent diabetes in patients and their non-diabetic family members. Br Med J 292:1419-1422

25. Price DE, Burden AC 1992 Growth of children before onset of diabetes. Diabetes Care 15:1393-1395

26. Hoskins PJ, Leslie RDG, Pyke DA 1985 Height at diagnosis of diabetes in children: A study in identical twins. Br Med J 290:278-280

27. Leslie RDG, Lo S, Millward BA, Honour J, Pyke DA 1991 Decreased growth velocity before IDDM onset. Diabetes 40:211-216

28. Kjaer K, Hagen C, Sandf H, Eshfy O 1992 Epidemiology of menarche and menstrual disturbances in an unselected group of women with insulin-dependent diabetes mellitus compared to controls. J Clin Endocrinol Metab 75:524-529

29. Bourguignon J-P 1988 Linear growth as a function of age at onset of puberty and sex steroid dosage: therapeutic implications. Endocr Rev 9:467-488

30. Vanelli M, de Fanti A, Adinolfi B, Ghizzoni L 1992 Clinical data regarding the growth of diabetic children. Horm Res 37(suppl 3):65:69 